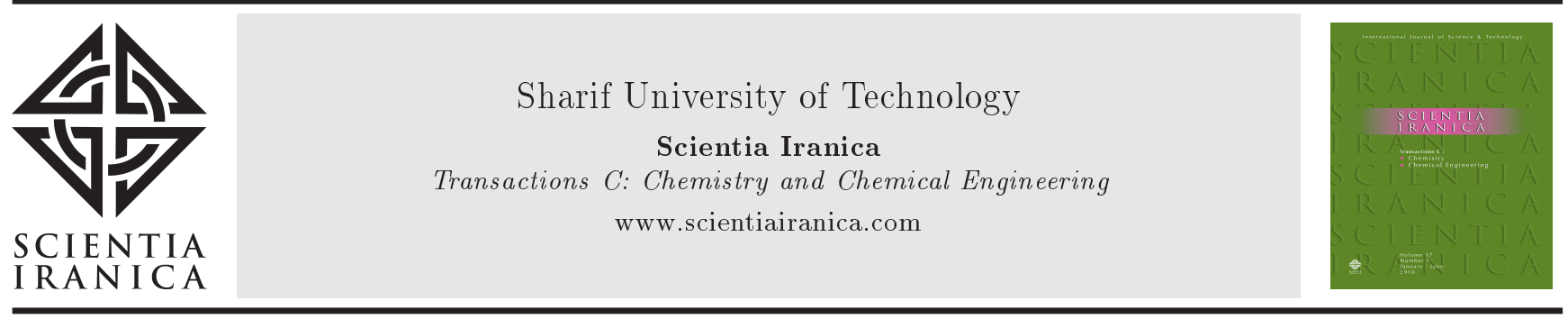

Research Note

\title{
Influence of the process parameters on the foam fractionation treatment of olive mill wastewater
}

\author{
S. Matavos-Aramyan*, M. Ghazi-MirSaeed, A. Saeedi-Emadi, M. Nemati \\ and S. Neysari
}

Department of Chemical and Materials Engineering, Shiraz Branch, Islamic Azad University, Shiraz, Iran.

Received 19 May 2015; received in revised form 5 June 2016; accepted 29 October 2016

\author{
KEYWORDS \\ Foam fractionation; \\ Fractional factorial \\ design; \\ Olive mill wastewater; \\ COD removal; \\ Effluent treatment.
}

\begin{abstract}
Olive Mill Wastewater (OMW) is a highly organic load waste produced by the three-phase decanter system used in the processing of olives for oil that has phytotoxic and antibacterial phenolic compounds, which help this waste to resist biological degradation. Foam fractionation has not yet been studied with regard to its potential for treatment of such wastewaters. In the present study, this technique was investigated in a simple model system. The effects of different operational conditions, namely, surfactant concentration, process time, $\mathrm{pH}$, and gas flow rate, were evaluated in this study. Statistical analysis of the fractional factorial design revealed that surfactant concentration, $\mathrm{pH}$, and gas flow rate were the most influential process parameters. Low surfactant concentration and $\mathrm{pH}$ of 3-4 were found to be advantageous in terms of good Chemical Oxygen Demand (COD) removal. More than $80 \%$ of COD was removed through a single-stage foam fractionation process. This method has proved to be a feasible technique for the OMW effluent treatment.

(C) 2016 Sharif University of Technology. All rights reserved.
\end{abstract}

\section{Introduction}

Olive Mill Wastewater (OMW) is generated by the olive oil mills during the extraction of olive oil [1]. Around $6 \times 10^{6} \mathrm{~m}^{3}$ of OMW is produced yearly worldwide, of which $98 \%$ is produced in the Mediterranean basin [2]. The disposal of OMW is a problematic issue in the countries that are active in this field. High Chemical Oxygen Demand (COD) of OMW coupled with its phenol content inhibits the natural organic load degrading capability of the micro-flora in water bodies [3]. In most cases, these waters are dumped into the environment untreated. The inadequate and uncontrolled disposal methods of OMW to the water bodies pose an environmental concern as these effluents contain appreciable amounts of COD and BOD

*. Corresponding author. Fax: +98218978 1867

E-mail address: s.matavos@gmail.com (S.

Matavos-Aramyan) concentrations and high amounts of microbial growthinhibiting compounds, such as phenolic compounds and tannins [4-6].

In the last few years, there has been a great effort to develop new solutions to the treatment of OMW, including sedimentation [7], sand filtration [8,9], ozonation [10], membrane filtration [11-13], neutralization with addition of acid, advanced chemical oxidation (Fenton reaction) [2,14], adsorption by activated carbon, and aerobic and anaerobic digestions $[15,16]$. In an industrial scale, these technologies have drawbacks because they are too expensive to have a wide application, are ineffective in meeting stringent effluent standards, and could result in a huge amount of sludge [15,17-20]. A method with high throughput, low costs for operation, and a simple plant concept should be employed to eliminate costly separation steps, particularly in the early stages when large matrix problems can be expected [21-23].

Adsorptive bubble separation, including foam 
fractionation, is based on the selective adsorption or attachment of materials onto the surfaces of gas bubbles rising through a solution [21,24]. The foam fractionation of ions is similar to ion flotation, but uses an excess of surfactant or a proper frother to produce stable foam [18-20,25]. During foam fractionation, gas bubbles are introduced into a liquid, which contains surface-active substances [26]. Foam formation occurs when surface-active molecules attach to the gas-liquid interface of the introduced bubbles. The foam formation can be caused by dissolved or dispersed substances. The surface tension of the interface is decreased and the foam is stabilized. Thus, the formed bubbles create an emerging foam column above the liquid level. The entrained liquid eventually drains back into the feed solution. This causes the foam to become dryer while rising [27-29]. Coalescence and disproportionation inside the dry foam increase bubble size. Thus, the concentration of surface-active substances between lamellae and Plateau borders increases [25]. The emerging foam column can be diverted into a separate vessel, where the foam is collapsed, e.g. mechanically or by decreased pressure. The collapsed foam, called foamate, comprises an enriched solution of surface-active components [30,31]. This principle can be used for the separation of organic substances from polluted industrial wastewaters. Such process offers many advantages for the treatment of industrial wastewaters compared to other treatment processes, including low space and energy requirements; simple plant design, operation, and scale-up; and low capital and operating costs $[19,32]$. Not only surfactants are removed by adsorption at the air-liquid interfaces, but other components that form complexes with the surfactants also tend to be concentrated [20,21,33]. Foam fractionation has some other major advantages over other techniques in the field of OMW treatment. There are no solvents required during this process, because only air or inert gases are involved [34-37]. In terms of sustainability, this process can thus be considered as 'green' [38]. Unlike solvent extraction processes, no co-extraction of other compounds such as fatty acids and chlorophyll is required [39].

Foam fractionation is subject to various influencing parameters which, furthermore, are not necessarily independent of each other. For this reason, this process was investigated by means of Design of Experiments (DoE). DoE has shown its benefit in the establishment of foam fractionation in biotechnological applications [21-24,40] and oxidative treatment of OMW [25$27,41]$, for example. The simultaneous variation of several process parameters combined with statistical analysis is advantageous with regard to the smaller number of experiments compared to the conventional concept of "one factor at a time".

The scope of this study was to evaluate such a technique for the OMW treatment. The influence of $\mathrm{pH}$, surfactant concentration, process time, and gas flow rate was investigated by fractional factorial design in order to find the most economical and effective process conditions, which could make this technique exploitable for treating OMW at industrial scales.

\section{Material and methods}

\subsection{Collection and preservation of $O M W$}

Fresh OMW was collected during the 4th quarter of 2014 from an industrial estate in Isfahan. The OMW samples were collected in 5 -L plastic containers and transported immediately to the laboratory and stored at approximately $7^{\circ} \mathrm{C}$. They were digested in their original form, which means that they were not subjected to any alteration. The physicochemical characterization of OMW is presented in Table 1.

\subsection{Analytical procedures}

The COD analyses were performed by the dichromate closed reflux Colorimetric Method using a Hach DR2010 Model spectrophotometer in accordance with Standard Methods. Total polyphenols were determined spectrophotometrically according to the FolinCiocalteau Method [40]. Other wastewater parameters were analyzed according to Standard Methods. All pH values were determined with a scale-reading precision of \pm 0.01 on $\mathrm{HACH}$ H260G pH meter. Nitrogen, $5 \mathrm{~N}$ grade, was distributed by Iranian Electronic Industries (IEI). The flow rate of nitrogen was regulated by a GCR Compact Regulator of HTK Hamburg GmbH (Hamburg, Germany).

\subsection{Chemicals}

Cetyltrimethylammonium bromide (CTAB) was purchased from $\mathrm{BDH}$ and was of analytical grade. $\mathrm{HCl}$ $(37 \%)$ and $\mathrm{NaOH}(97 \%)$ were obtained from SigmaAldrich (Seelze, Germany). The CTAB solution $(10 \mathrm{mg} / \mathrm{mL})$ was dissolved in pure water under slight warming.

\subsection{Apparatus}

The experiments were conducted in a batch system, shown in Figure 1. The column was a Pyrex cylinder with internal diameter of $d_{i}=10.0 \mathrm{~cm}$. The column

Table 1. Physico-chemical characterization of OMW.

\begin{tabular}{ll}
\hline \multicolumn{1}{c}{ Parameter } & \multicolumn{1}{c}{ Value } \\
\hline $\mathrm{pH}$ & 4.7 \\
$\mathrm{COD}$ & $58.42 \mathrm{gL}^{-1}$ \\
$\mathrm{BOD}_{5}$ & $9.67 \mathrm{gL}^{-1}$ \\
Total suspended solids & $5.43 \mathrm{gL}^{-1}$ \\
Total polyphenols & $0.41 \mathrm{gL}^{-1}$ \\
Biodegradability $\left(\mathrm{BOD}_{5} / \mathrm{COD}\right)$ & 0.165 \\
\hline
\end{tabular}




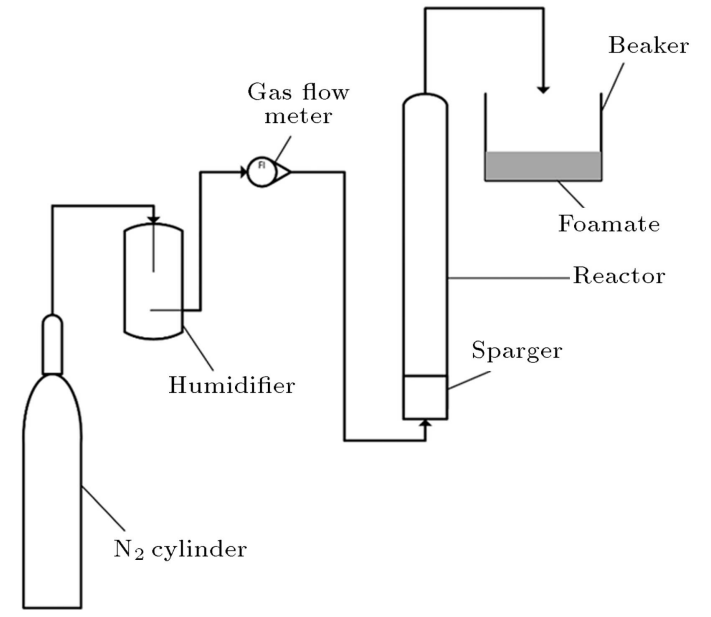

Figure 1. Experimental setup for foam fractionation.

was equipped with a sintered glass frit (ASTM 4060 type $\mathrm{C}$ ). The bubbles formed by this type of frit had diameters that were distributed roughly between 0.4 and $1.2 \mathrm{~mm}$. Nitrogen gas was passed through a fritted wash bottle filled with water to humidify it and minimize evaporation losses in the feed solution. To ensure good passage of the gas through the pores of the frit, the nitrogen flow was always activated in advance to fill the glass column with liquid via a funnel. Through a $\Pi$-formed glass tube, the rising foam was piped into a beaker. The schematic of the experimental setup is presented in Figure 1. All experiments were carried out at ambient temperature, $16 \pm 2{ }^{\circ} \mathrm{C}$. After each experiment, the column was thoroughly cleaned with water and acetone and let dry before further use.

\subsection{Experimental procedures}

A 30-minute period was assigned to all solutions prior to beginning the experiments for equilibration considerations [41]. The volume of the feed solution was always $50 \mathrm{~mL}$. The $\mathrm{pH}$ of the stock solutions was adjusted by adding normal solutions of either $\mathrm{HCl}$ or $\mathrm{NaOH}$ before starting the experiments. Samples analysis began at the end of each experiment by pipetting aliquots of liquid from the reactor solution.

The performance of foam fractionation is expressed by one criterion, i.e. Enrichment Factor (EF), which describes the ratio of the concentration of the target compound in the feed $\left(\mathrm{COD}_{\text {feed }}\right)$ minus the concentration of the target compound in the foamate $\left(\mathrm{COD}_{\text {foamate }}\right)$ to that in the feed, all subtracted from 1 (Eq. (1)). The higher the EF, the richer is the foamate in the COD.

$$
\mathrm{EF}=1-\frac{\mathrm{COD}_{\text {feed }}-\mathrm{COD}_{\text {fomate }}}{\mathrm{COD}_{\text {feed }}} .
$$

\subsection{Design of experiments}

The influence of the 4 process parameters, i.e. pH, surfactant concentration, process time, and gas flow rate, should be determined. Thus, based on a $2^{4}$ plan, a fractional factorial design matrix is developed for optimization of the foam fractionation process. Blocked fractional factorial design reveals the main effects and interaction effects on the performance criteria of the 4 variables. Gas flow rate should not be lower than $20 \mathrm{~mL} / \mathrm{min}$ to sustain formation and discharge of foam. Furthermore, the upper $\mathrm{pH}$ value is limited to $\mathrm{pH} 7$. The enrichment factor is employed as the response factor for the process of foam fractionation.

\section{Results and discussion}

\subsection{Statistical analysis}

3.1.1. Enrichment factor

The influence of the input variables on each response factor is visualized in Pareto charts (Figure 2). The length of each bar represents the extent of the influence of the corresponding parameter. EF is negatively influenced by concentration of CTAB and $\mathrm{pH}$. This means these two factors on a high level result in a low EF. In contrast, higher gas flow rate leads to high enrichment in the foam. Three interaction effects (AD, $\mathrm{AB}$, and $\mathrm{AC}$ ) are significant enough for $\mathrm{EF}$ to be taken into account. This means the effect of such a factor is influenced by the level of the second factor. The impact of the individual input variables on each response factor can be depicted in the plot of main effects. The diagram shows the calculated values of EF by the fitted model, which are obtained by increasing the factors from their minimum (left) to their maximum level (right). The slope and orientation of the graphs reflect the extent and the character (negative/positive) of the impact. Only significant effects are considered. For $\mathrm{EF}$, the plot of main effects (Figure 3 ) clearly illustrates that high levels of two input variables (CTAB and $\mathrm{pH}$ ) result in a decrease of $\mathrm{EF}$. In contrast, changing the gas flow rate value from a low to a high level leads to high

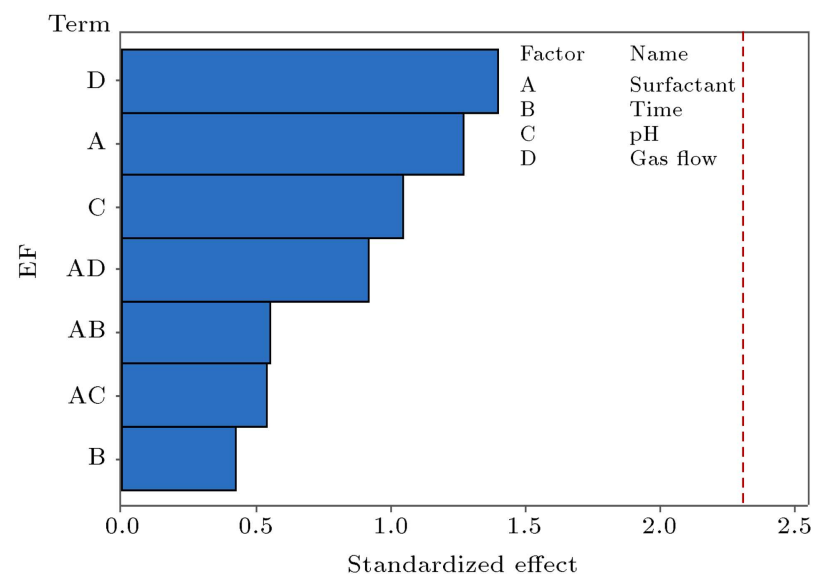

Figure 2. Pareto diagram for enrichment factor in the foamate. No significant effects are observed since no column crosses the vertical line (significance level 0.05). 


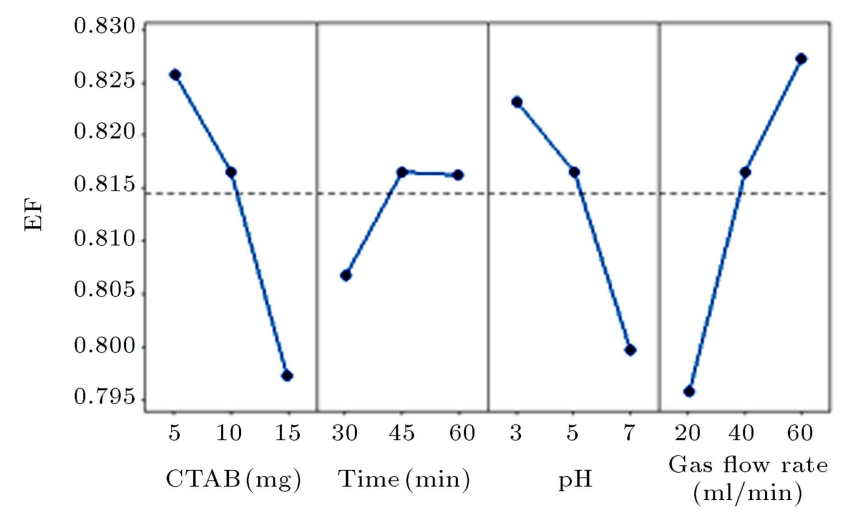

Figure 3. Plot of the main effects for enrichment factor in the foamate. Minimum (right side) and maximum (left side) levels are indicated for each input variable.

enrichment factors. Process time should be considered to remain at optimum values. As it is demonstrated, the extent of the influence and the impact of the process parameters (Figures 2 and 3, respectively) are in good agreement with each other.

\subsubsection{Effect of $C T A B$ concentration (A)}

One of the most important impact factors on EF was found to be CTAB concentration. The tested concentrations in this study were below the critical micelle concentration of CTAB, which is $9.2 \times 10^{-4} \mathrm{M}$ [39]. As a foaming agent, CTAB influenced the wetness of the foam. The higher its concentration, the "wetter" is the foam. This implies a high content of entrained bulk solution in the foam. This results in an increased discharge of liquid phase with the foamate resulting in low EF. Thus, for the optimization of the response factor, a compromise has to be found between this input variable and others which will be mentioned later.

\subsubsection{Effect of process time (B)}

Amongst the investigated process parameters, "time" has shown the lowest impact on the response factor. The optimum process time in this study is pointed out to be around 45 minutes. Lower process time has negative impact on the response since the time required for the adsorption to take place is not adequate. Contrary to the latter, since the foamate volume increases over time, longer process time also has negative impact on the response. This means that process time has deeper influence on the wetness of the foamate than the gas flow rate and should be monitored carefully.

\subsubsection{Effect of $p H(C)$}

The $\mathrm{pH}$ effect was particularly studied through experiments, which showed the COD reduction of olive mill wastewater. These results also revealed that foam fractionation was a highly $\mathrm{pH}$-sensitive process. The $\mathrm{pH}$ value of the feed solution determines the degree of deprotonated organic pollutants. The lower the deprotonation, the higher the adsorption. For the response factor, $\mathrm{pH}$ 3-4 was found to be optimum. Many organic molecules can undergo a series of autoxidation reactions in the basic to neutral conditions. Such reactions result in production of some species which, consequently, have poor interaction with the cationic surfactant. Thus, to prevent autoxidation reactions, lower $\mathrm{pH}$ is preferred to near-neutral and basic conditions.

\subsubsection{Effect of gas flow rate $(D)$}

Statistical analysis based on the DoE (Table 2) revealed a positive effect of gas flow rate on EF. Gas flow rate significantly influences the wetness of the rising foam and, therefore, determines the liquid fraction of the foamate. Low gas flow rates make the foam rise slowly inside the column, providing more time for the processes like coalescence and drainage of superfluous liquid. The former is based on the tendency of smaller gas bubbles to combine into one bigger gas bubble with a reduced surface compared to the aggregate surface

Table 2. Fractional factorial design in four blocks for four variables (randomized).

\begin{tabular}{|c|c|c|c|c|c|c|c|}
\hline $\begin{array}{c}\text { Run } \\
\text { number }\end{array}$ & Block & $\mathbf{A}$ & B & $\mathrm{C}$ & $\mathbf{D}$ & EF & $\begin{array}{c}\text { Phenolic } \\
\text { removal } \\
(\%)\end{array}$ \\
\hline 1 & 3 & 0 & 0 & 0 & 0 & 0.782 & 91.21 \\
\hline 2 & 3 & - & + & - & + & 0.851 & 99.26 \\
\hline 3 & 3 & 0 & 0 & 0 & 0 & 0.856 & 99.84 \\
\hline 4 & 3 & 0 & 0 & 0 & 0 & 0.830 & 99.81 \\
\hline 5 & 3 & + & - & + & - & 0.758 & 88.41 \\
\hline 6 & 2 & + & + & - & - & 0.791 & 92.26 \\
\hline 7 & 2 & 0 & 0 & 0 & 0 & 0.840 & 97.98 \\
\hline 8 & 2 & 0 & 0 & 0 & 0 & 0.804 & 93.77 \\
\hline 9 & 2 & - & - & + & + & 0.818 & 95.49 \\
\hline 10 & 2 & 0 & 0 & 0 & 0 & 0.825 & 96.17 \\
\hline 11 & 4 & + & + & + & + & 0.798 & 93.08 \\
\hline 12 & 4 & - & - & - & - & 0.809 & 94.66 \\
\hline 13 & 4 & 0 & 0 & 0 & 0 & 0.831 & 96.93 \\
\hline 14 & 4 & 0 & 0 & 0 & 0 & 0.839 & 97.86 \\
\hline 15 & 4 & 0 & 0 & 0 & 0 & 0.763 & 89.07 \\
\hline 16 & 1 & 0 & 0 & 0 & 0 & 0.790 & 92.12 \\
\hline 17 & 1 & 0 & 0 & 0 & 0 & 0.836 & 97.51 \\
\hline 18 & 1 & + & - & - & + & 0.842 & 98.29 \\
\hline 19 & 1 & - & + & + & - & 0.825 & 96.23 \\
\hline 20 & 1 & 0 & 0 & 0 & 0 & 0.802 & 93.71 \\
\hline \multicolumn{3}{|l|}{ Variables } & - & + & 0 & & \\
\hline \multicolumn{3}{|c|}{ A: Surfactant (mg) } & 5 & 15 & 10 & & \\
\hline \multicolumn{3}{|c|}{ B: Time (min) } & 20 & 60 & 45 & & \\
\hline \multicolumn{3}{|c|}{$\mathrm{C}: \mathrm{pH}$} & 3 & 7 & 5 & & \\
\hline \multicolumn{3}{|c|}{ D: Gas flow rate $(\mathrm{ml} / \mathrm{min})$} & 20 & 60 & 40 & & \\
\hline
\end{tabular}


of the small bubbles. Liberated water molecules can then drain off back to the feed while surface-active compounds stay adsorbed at the gas-liquid interface within the foam. Higher gas flow rates result in much more turbulence in the column; therefore, the impact between bubbles and the sample significantly increases. Although foamate volume increases, the influence of the increased impact prevails too much over this problematic angle of the experiment so that in the end, the target concentration in surface-active molecules is higher.

\subsection{Optimization}

Only statistically significant effects were taken into account in identifying optimum parameters for the foam fractionation process in the statistical model. As demonstrated, all main effects were statistically significant for the response factor. However, one has to keep in mind that the requested performance criterion of effective foam fractionation was a maximum Enrichment Factor (EF); therefore, the efficiency of extraction increases with the factors which have positive impact on the enrichment factor. Upper and lower limits of the input variables were determined by the corner and center points.

The foam fractionation process aims at generating foam highly enriched in the target molecules. In addition, the target should be extracted in high quantities. Therefore, in a second step, the model was used to calculate optimum parameters for achieving high EF. The response was weighted 1 in the corresponding optimization.

Considering these lower and upper limits of the experimental design, values of process parameters for achieving highest EF were calculated (Table 3). "Desirability" reflects the experimenter's acceptance of the degree by which the desired optimization can be fulfilled. It can vary from 0 to 1 , with 1 corresponding to the optimum for all response factors. In our optimization process, desirability reached 0.930 .

If all the factors are taken into account, one can get the following equation by using a linear parameter

Table 3. Predicted optimum values for the operational parameters to achieve maximum enrichment in the foam.

\begin{tabular}{|c|c|c|c|}
\hline Factor & $\begin{array}{c}\text { Lower } \\
\text { limit }\end{array}$ & $\begin{array}{l}\text { Upper } \\
\text { limit }\end{array}$ & $\begin{array}{c}\text { Optimum } \\
\text { for } \\
\text { maximum } \\
\text { EF }\end{array}$ \\
\hline A: Surfactant (mg) & 3.00 & 21.00 & 7.29 \\
\hline B: Time (min) & 15.00 & 50.00 & 42.00 \\
\hline $\mathrm{C}: \mathrm{pH}$ & 2.00 & 6.00 & 3.00 \\
\hline D: Gas flow rate $(\mathrm{ml} / \mathrm{min})$ & 20.00 & 80.00 & 55.00 \\
\hline
\end{tabular}

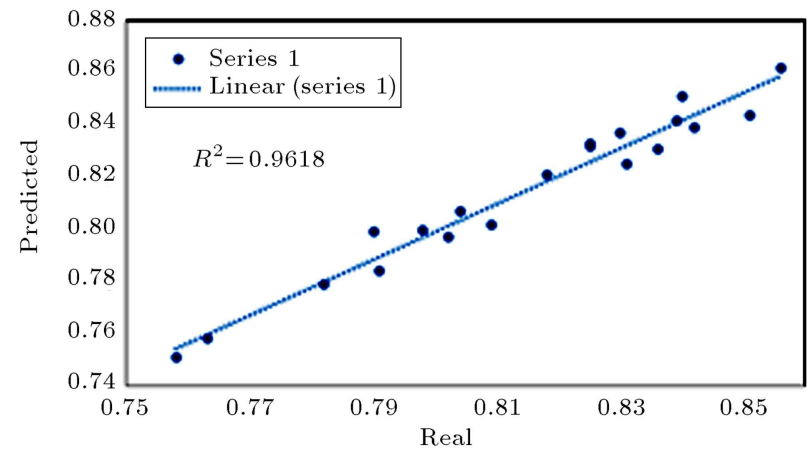

Figure 4. EF values: Predicted vs. real.

model based on the actual factors:

$$
\begin{aligned}
\mathrm{EF}= & 0.790+0.0005 \mathrm{~A}+0.00138 \mathrm{~B}+0.0020 \mathrm{C} \\
& -0.00055 \mathrm{D}-0.000107 \mathrm{AB}-0.00078 \mathrm{AC} \\
& +0.000133 \mathrm{AD} .
\end{aligned}
$$

The analysis of variance (ANOVA) table of the statistical analysis is provided in Table 4 . As can be observed, although the $P$-values of the factors, with complete agreement with Pareto chart, indicate that there is no significant effect from any of the four factors, the $P$-value of the model shows the significance of the model itself. It can be emphasized that the predicted values obtained from the empirical model (Eq. (2)) are in very good agreement with actual experimental data.

The observed mean values of the experiments were compared with the predicted values (Figure 4). The figure shows that the model is acceptable and the proposed empirical model is suitable for predicting the EF value. The regression squared (R-sq.) of the model is equal to 0.9618 and is in good agreement with the adjusted R-sq., which is 0.9080 . The $F$-value is 35.11 , which shows that the model equation is a safe model for the purpose of system navigation.

\section{Conclusion}

Several methods have so far been proposed for OMW treatment; however, very little research has been performed regarding the treatment of OMW using foam fractionation technique. In this study, a simple low-cost method was proposed for treating the OMW produced by the olive oil mills. The overall results of this study indicate that the application of foam fractionation is a feasible method to partially treat olive mill wastewaters, allowing to achieve a significant decrease of COD. Design of experiments was used to find optimum experimental conditions for effective COD removal (high EF) process. Results prove that more than $80 \%$ of the OMW COD can be removed through a single stage in fractionation process. This 
Table 4. ANOVA of the statistical analysis.

\begin{tabular}{lccccc}
\hline \multicolumn{1}{c}{ Source } & Sum of squares & $\boldsymbol{R}^{\mathbf{2}}$ & Adj. $\boldsymbol{R}^{\mathbf{2}}$ & $\boldsymbol{F}$-value & $\boldsymbol{P}$-value \\
\hline Model & $3.983 \mathrm{E}-003$ & 0.9618 & 0.9080 & 35.11 & 0.043 \\
A: Surfactant & $2.420 \mathrm{E}-004$ & 0.8820 & 0.8715 & 9.17 & 0.149 \\
B: Time & $1.800 \mathrm{E}-003$ & 0.9492 & 0.9122 & 4.18 & 0.482 \\
C: pH & $1.250 \mathrm{E}-003$ & 0.9211 & 0.8956 & 8.71 & 0.241 \\
D: Gas flow rate & $6.912 \mathrm{E}-004$ & 0.8677 & 0.8273 & 11.40 & 0.107 \\
AB & $2.383 \mathrm{E}-003$ & 0.9019 & 0.8887 & 5.98 & 0.519 \\
AC & $3.379 \mathrm{E}-004$ & 0.9887 & 0.9530 & 5.07 & 0.503 \\
AD & $2.764 \mathrm{E}-003$ & 0.9535 & 0.9133 & 7.39 & 0.587 \\
BC & $5.945 \mathrm{E}-004$ & 0.8891 & 0.8664 & 2.66 & 0.811 \\
BD & $1.913 \mathrm{E}-003$ & 0.9114 & 0.8976 & 3.79 & 0.634 \\
CD & $3.566 \mathrm{E}-003$ & 0.8940 & 0.8566 & 1.90 & 0.890 \\
Curvature & $3.333 \mathrm{E}-006$ & & & & \\
Residual & 0.011 & & & & \\
Lack of fit & $1.932 \mathrm{E}-003$ & & & & \\
Pure error & $8.650 \mathrm{E}-003$ & & & & \\
Cor. total & 0.015 & & & & \\
\hline
\end{tabular}

study also pointed out that low concentrations of surfactant in acidic conditions with a proper gas flow rate were favorable in this process.

\section{References}

1. Ben Sassi, A., Ouazzani, N., Walker, G.M., Ibnsouda, S., El Mzibri, M. and Boussaid, A. "Detoxification of olive mill wastewaters by Moroccan yeast isolates", Biodegradation, 19, pp. 337-346 (2008).

2. Zorpas, A.A. and Costa, C.N. "Combination of Fenton oxidation and composting for the treatment of the olive solid residue and the olive mile wastewater from the olive oil industry in Cyprus", Bioresour. Technol., 101, pp. 7984-7987 (2010).

3. Tsioulpas, A., Dimou, D., Iconomou, D. and Aggelis, G. "Phenolic removal in olive oil mill wastewater by strains of Pleurotus spp. in respect to their phenol oxidase (laccase) activity", Bioresour. Technol., 84, pp. 251-257 (2002).

4. Hanifi, S. and El Hadrami, I. "Olive mill wastewaters: diversity of the fatal product in olive oil industry and its valorisation as agronomical amendment of poor soils: a review", J. Agronomy, 8, pp. 1-13 (2009).

5. Kallel, M., Belaid, C., Boussahel, R., Ksibi, M., Montiel, A. and Elleuch, B. "Olivemill wastewater degradation by Fenton oxidation with zero-valent iron and hydrogen peroxide", J. Hazard. Mater., 163, pp. 550-554 (2009).

6. Lucas, M.S. and Peres, J.A. "Removal of COD from olive mill wastewater by Fenton's reagent: kinetic study", J. Hazard. Mater., 168, pp. 1253-1259 (2009).

7. Achak, M., Ouazzani, N., Yaacoubi, A. and Mandi, L. "Modern olive mill effluent characterization and their treatment by coagulation-flocculation using lime and aluminum sulphate", J. Water. Sci., 21, pp. 53-67 (2008).

8. Achak, M., Mandi, L. and Ouazzani, N. "Removal of organic pollutants and nutrients from olive mill wastewater by a sand filter", J. Environ. Manage., 90, pp. 2771-2779 (2009).

9. Achak, M., Ouazzani, N. and Mandi, L. "Treatment of modern olive mill effluent by infiltration-percolation on a sand filter", J. Water. Sci, 22, pp. 421-433 (2009).

10. Chedeville, O., Debacq, M. and Porte, C. "Removal of phenolic compounds present in olive mill wastewaters by ozonation", Desalination, 249, pp. 865-869 (2009).

11. Paraskeva, C.A., Papadakis, V.G., Tsarouchi, E., Kanellopoulou, D.G. and Koutsoukos, P.G. "Membrane processing for olive mill wastewater fractionation", Desalination, 213, pp. 218-229 (2007).

12. Dhaouadi, H. and Marrot, B. "Olive mill wastewater treatment in a membrane bioreactor: process feasibility and performances", Chem. Eng. J., 145, pp. 225231 (2008).

13. Akdemir, E.O. and Ozer, A. "Investigation of two ultrafiltration membranes for treatment of olive oil mill wastewater", Desalination, 249, pp. 660-666 (2009).

14. Gomec, C.Y., Erdim, E., Turan, I., Aydin, A.F. and Ozturk, I. "Advanced oxidation treatment of physicochemically pre-treated olive mill industry effluent", $J$. Environ. Sci. Health B, 42, pp. 741-747 (2007).

15. Azbar, N., Keskin, T. and Catalkaya, E.C. "Improvement in anaerobic degradation of Olive Mill Effluent (OME) by chemical pretreatment using batch systems", Biochem. Eng. J., 38, pp. 379-383 (2008). 
16. Boubaker, F. and Ridha, B.C. "Modelling of the mesophilic anaerobic co-digestion of olive mill wastewater with olive mill solid waste using anaerobic digestion model No. 1 (ADM1)", Bioresour. Technol., 99, pp. 6565-6577 (2008).

17. Zheng, H., Zhang, D., Guo, K., Dong, K., Xu, D. and $\mathrm{Wu}, \mathrm{Z}$. "Online recovery of nisin during fermentation coupling with foam fractionation", J. Food Eng., 162, pp. 25-30 (2015).

18. Beuker, J., Steier, A., Wittgens, A., Rosenau, F., Henkel, M. and Hausmann, M. "Integrated foam fractionation for heterologous rhamnolipid production with recombinant Pseudomonas putida in a bioreactor", AMB Expr., 2, pp. 6-11 (2016).

19. Lia, R., Wu, Z., Wangb, Y., Ding, L. and Wang, $\mathrm{Y}$. "Role of $\mathrm{pH}$-induced structural change in protein aggregation in foam fractionation of bovine serum albumin", Biotech. Reports., 9, pp. 46-52 (2016).

20. Kou, Q., Li, J., Zhao, B. and Wu, Z.l. "Recovery of streptomycin sulfate from the wastewater using foam fractionation coupled with adsorption separation for reusing sodium dodecyl sulfate", J. Chem. Technol. Biot., 90, pp. 874-879 (2015).

21. Kugler, J.H., Goll, C.M., Hansen, S.H., Volp, A.R., Kirschhofer, F., Kuhl, B., Weiss, G.B., Luy, B., Syldatk, C. and Hausmann, R. "Glycolipids produced by Rouxiella sp. DSM 100043 and isolation of the biosurfactants via foam-fractionation", $A M B$ Expr., $\mathbf{5}$, pp. 82-93 (2015).

22. Shao, W., Zhang, J., Feng, A., Pan, X. and Xiao, Z. "Removal of $\mathrm{Ni}$ (II) in aqueous solutions by foam fractionation", Desalination Water Treat., 53, pp. 1426-1433 (2015).

23. Arulmozhi, M., Meer, K.M., Begum, S. and Anantharaman, N. "Continuous foam fractionation of chromium (VI) ions from aqueous and industrial effluents", Desalination Water Treat., 53, pp. 1664-1674 (2015).

24. Cowarda, T., Lee, J.G.M. and Caldwell, G.S. "Harvesting microalgae by CTAB-aided foam flotation increases lipid recovery and improves fatty acid methyl ester characteristics", Biomass Bioenerg., 67, pp. 354362 (2014).

25. Liu, W., Wu, Z.L., Wang, Y.J., Li, R., Yin, N.N. and Jiang, J.X. "Separation of isoflavone aglycones using chitosan microspheres from soy whey wastewater after foam fractionation and acidic hydrolysis", J. Ind. Eng. Chem., 25, pp. 138-144 (2015).

26. Grassia, P., Ubal, S., Giavedoni, M.D., Vitasari, D. and Martin, P.J. "Surfactant flow between a Plateau border and a film during foam fractionation", Chem. Eng. Sci., 143, pp. 139-165 (2016).

27. Lu, J., Li, Y., Zhang, S. and Sun, Y. "Removal of trace $\mathrm{Cd} 2^{+}$from aqueous solution by foam fractionation", $J$. Hazard. Mater., 286, pp. 466-473 (2015).
28. Hofmann, A., Schembecker, G. and Merz, J. "Role of bubble size for the performance of continuous foam fractionation in stripping mode", Colloids and Surfaces A., 473, pp. 85-94 (2015).

29. Zhang, Z., Wua, Z. and Liu, G. "Interfacial adsorption of methyl orange in liquid phase of foam fractionation using dodecyl dimethyl betaine as the collector", $J$. Ind. Eng. Chem., 28, pp. 184-189 (2015).

30. Guo, S., Wu, Z.L., Liu, W., Huang, D., Li, H. and $\mathrm{Hu}$, N. "Enrichment and isolation of phenol from its aqueous solution using foam fractionation", In Proteomics in Foods: Principles and Applications, Food Microbiology and Food Safety, Springer (2016).

31. Prudich, M.E. "Alternative solid/liquid separations", In R.H. Perry, D.W. Green, Eds., Perry's Chemical Engineers' Handbook, Eighth Ed., McGraw-Hill Professional, New York (2007).

32. Rubio, J., Souza, M. and Smith, R. "Overview of flotation as a wastewater treatment technique", Miner. Eng., 15, pp. 139-155 (2002).

33. Wong, C., Hossain, M. and Davies, C. "Performance of a continuous foam separation column as a function of process variables", Bioprocess Biosyst. Eng., 24, pp. 73-81 (2001).

34. Yapijakis, C. and Wang, L.K. "Treatment of soap and detergent", In L.K. Wang, Y. Hung, H.H. Lo, C. Yapijakis, Eds., Waste Treatment in the Process Industries, First Ed., CRC Press, New York (2005).

35. Merz, J., Burghoff, B., Zorn, H. and Schembecker, G. "Continuous foam fractionation: performance as a function of operating variables", Sep. Purif. Technol., 82, pp. 10-18 (2011).

36. Merz, J., Zorn, H., Burghoff, B. and Schembecker, G. "Purification of a fungal cutinase by adsorptive bubble separation: a statistical approach", Colloids Surf. A, 382, pp. 81-87 (2011).

37. Chen, Y.-C. and Parlar, H. "Enrichment behavior of immunoglobulin by foam fractionation using response surface methodology", Sep. Purif. Technol., 107, pp. 102-108 (2013).

38. Aksay, S. and Mazza, G. "Optimization of protein recovery by foam separation using response surface methodology", J. Food Eng., 79, pp. 598-606 (2007).

39. Ahmadi, M., Vahabzadeh, F., Bonakdarpour, B., Mofarrah, E. and Mehranian, M. "Application of the central composite design and response surface methodology to the advanced treatment of olive oil processing wastewater using Fenton's peroxidation", $J$. Hazard Mater., 123, pp. 187-195 (2005). 
40. Singleton, V.L. and Rossi, J.A. "Colorimetry of total phenolics with phosphomolybdic-phosphotungstenic acid reagents", Am. J. Enol. Viticult., 16, pp. 144-158 (1965).

41. Wu, Q., Apte, S.C., Batley, G.E. and Bowels, K.C. "Determination of the mercury complexation capacity of natural waters by anodic stripping voltammetry", Anal. Chim. Acta, 350, pp. 129-134 (1997).

\section{Biographies}

Sina Matavos-Aramyan received the AS degree in Chemical Industries from Shahid Rajaei Technical University in 2008. He owns a BSc degree in Chemical Industries Engineering, received in 2011, and an MSc degree in Chemical Engineering, received in 2015, both from Islamic Azad University (IAU), Iran. $\mathrm{He}$ is the author of many peer-reviewed technical papers and serves as one of the reviewers in the board of Springer Science publishing house. He is also the assignee and inventor of many patented inventions and an author of five academic books published in both English and Farsi languages all over the world. His research interests involve radical chemistry, advanced oxidation processes, hazardous materials control and elimination, Fischer-Tropsch process, and organometallic catalysts. He is a Member of Young Researchers and Elite Club, Member of International Federation of Inventors Association (IFIA), and Member of Iran Nano Technology Initiative Council. He is currently the CEO and Deputy Chairman of Raazi Environmental Protection Foundation (REPF), which is a research and technical council for the hazardous materials control, and environmental protection and supervision.

Mahdie Ghazi-MirSaeed received her BSc and MSc degrees in Chemical Engineering, in 2010 and 2015, respectively, from IAU. Her research interests include separation processes and molecular sieves and she is specialized in the thermokinetics processes. She is the author of two academic books, written in both English and Farsi languages, and has some peerreviewed papers in the field of chemical engineering. She has also one patented invention in the field of chemical engineering.

Ali Saeedi-Emadi received his BSc and MSc degrees in Chemical Engineering from Iau, in 2006 and 2015, respectively. His research interests involve separation processes, hazardous materials control, organometallic catalysts, and chemical wastewater treatment. He is an author of three academic books, written in both English and Farsi languages, and has some peerreviewed papers in the field of chemical engineering. $\mathrm{He}$ is also the Chairman of Raazi Environmental Protection Foundation (REPF), which is a research and technical council for the hazardous materials control, and environmental protection and supervision.

Mohammad Nemati received his BSc in Chemical Engineering from Shiraz University and his MSc degree in Chemical Engineering, from IAU, in 2015. His research interests include conceptual design of chemical processes, pinch technology, mathematical modeling of industrial chemical processes, and modification of energy in petrochemical plants. He has some peerreviewed papers in the field of chemical engineering. He is currently the Chief Operating Officer of Iran's South Pars Gas Complex (SPGC), Phase 12.

Samaneh Neysari received her BSc and MSc degrees in Chemical Engineering, in 2010 and 2015, respectively, from IAU. Her research interests involve separation processes, hazardous materials control, membrane technology, and chemical wastewater treatment. She has participated in many international conferences and has presented some lectures in the field of chemical engineering. She is currently the Head of REPF's Research and Development Section. 